\title{
Bridging the Patient Engagement Gap in Research and Quality Improvement Utilizing the Henry Ford Flexible Engagement Model
}

\author{
Heather A. Olden \\ Sara Santarossa \\ Dana Murphy \\ Christine C. Johnson \\ Karen E. Kippen
}

Follow this and additional works at: https://aah.org/jpcrr

Part of the Other Public Health Commons, Primary Care Commons, Public Health Education and Promotion Commons, and the Quality Improvement Commons

\section{Recommended Citation}

Olden HA, Santarossa S, Murphy D, Johnson CC, Kippen KE. Bridging the patient engagement gap in research and quality improvement utilizing the Henry Ford flexible engagement model. J Patient Cent Res Rev. 2022;9:35-45. doi: 10.17294/2330-0698.1828

Published quarterly by Midwest-based health system Advocate Aurora Health and indexed in PubMed Central, the Journal of Patient-Centered Research and Reviews (JPCRR) is an open access, peer-reviewed medical journal focused on disseminating scholarly works devoted to improving patient-centered care practices, health outcomes, and the patient experience. 


\title{
Bridging the Patient Engagement Gap in Research and Quality Improvement Utilizing the Henry Ford Flexible Engagement Model
}

\author{
Heather A. Olden, MPH, Sara Santarossa, PhD, Dana Murphy, BA, Christine C. Johnson, PhD, \\ Karen E. Kippen, MSA \\ Patient-Engaged Research Center, Department of Public Health Sciences, Henry Ford Health System, Detroit, MI
}

\begin{abstract}
Purpose
This paper was intended to share a flexible engagement model (FEM) for organizing a structure to obtain patient input regarding health care operations and research, provide greater detail on recruitment, retention, and dissemination strategies, and demonstrate successes and potential applications in other health care settings.
\end{abstract}

Methods Utilizing a pragmatic approach, the Patient-Engaged Research Center (PERC) at Henry Ford Health System developed the FEM, a 7-step process to introduce interested patients/caregivers to the patient advisor program and to follow up with placements. PERC developed a meeting evaluation to measure participant satisfaction. Retention and dissemination methods to keep participants consistently engaged included monthly email blasts, an annual patient advisor retreat, and inviting patient advisors to attend/present at local and national conferences.

Results As of January 2020, the program had 419 patient advisors. Almost $50 \%$ self-reported as Caucasian and $31 \%$ as African American; $73 \%$ were women, and most were $45-74$ years of age. Recruitment methods proved effective, as $85 \%$ of advisors were initially engaged through print and digital marketing. Mean advisor orientation workshop evaluation scores regarding content, facilitators, and logistics were high, with all 4.5 or higher on a Likert scale of 1 (strongly negative) to 5 (strongly positive).

Conclusions Given the FEM's flexible nature and adaptability, PERC has been successful in effectively leveraging the patient voice and experiences in research and health care delivery. Further research could investigate the model's generalizability, return on investment, and how to formally embed its methodology institutionally. (J Patient Cent Res Rev. 2022;9:35-45.)

Keywords patient engagement; patient advisor; flexible engagement model; retention; dissemination; health services research

$\mathrm{P}$ atient engagement, defined by the Patient-Centered Outcomes Research Institute (PCORI) as the involvement of patients and other stakeholders throughout the planning, conduct, and dissemination of proposed projects, ${ }^{1}$ has become a major area of focus in health care improvement and clinical research nationally. Despite growing interest, patient engagement and retention models to support this endeavor have not been consistently defined or operationalized into practice. ${ }^{2,3}$ Patients' knowledge and perspectives have not traditionally been solicited, thus missing their potential contributions to identifying, improving, and implementing

Corresponding author: Heather A. Olden, 1325 Commonwealth Ave., Apt. 25, Allston, MA 02134 (heather.olden88@gmail.com) work and research processes that address health and health care challenges. However, the literature suggests that patients can contribute their care experiences to significantly influence health care improvements through assessment of the care environment, nonclinical aspects of care, and the prioritization of relevant research. ${ }^{4-7}$

Recently, the inclusion of patient input on projects has shown potential to ensure that evidence-based treatments are adopted in real-world practice ${ }^{6,8,9}$ and that quality improvement efforts result in improved health outcomes and reduced costs. ${ }^{5-7,10}$ More patient engagement is needed to ensure the care provided is truly patient-centered and that research addresses questions important to patients and families. It is imperative that health care institutions nationwide embrace this cultural shift from doing "to and for" the patient to "partnering with" by engaging them in the topics pertaining to research and care. Current lack of robust integration of the patient perspective in 
quality improvement efforts is likely to hamper progress on improving care outcomes. However, there is limited evidence in the literature on the return on investment for patient engagement activities. ${ }^{8-11}$ Gaps between strategy and practice may be amplified by the lack of a successful model that bridges health care-related disciplines with multidisciplinary stakeholders. ${ }^{10,12-15}$

In 2014, with funding through an Agency for Healthcare Research and Quality (AHRQ) R24 award, Henry Ford Health System's Patient-Engaged Research Center (PERC) began building patient-centered outcomes research infrastructure and developed a flexible engagement model (FEM) to recruit, train, and retain a diverse patient advisor (PA) pool to serve as a resource for quality improvement and research projects. PAs are patients and caregivers who share their experiences and insights with stakeholders to make health care and research more patient-centered by improving the patient/ study participant experience and project outcomes. PERC's FEM was created specifically to meet the needs of diverse stakeholders across platforms (eg, health systems, academic medical centers, research teams) and to support patient participation in clinical care, research, quality improvement, etc. The versatility of the FEM lies in the ability of the PAs to flex between various roles and contribute their expertise to funded research projects as well as other patient-centered activities such as building design and quality improvement projects.

Given the gap between patient engagement strategy and practice, the purpose of this paper is to comprehensively describe this FEM, provide greater detail on its recruitment, retention, and dissemination strategies, and demonstrate its initial success and potential application in other health care settings.

\section{METHODS}

There are four PA roles - health system advisor, research advisor, focus group advisor, and virtual advisor - supporting a variety of projects focused on quality improvement, research, patient experience, and design (Figure 1). With the objective of training, placing, and supporting PAs on projects throughout the health system, PERC developed a 7-step recruitment and retention process to keep PAs engaged in the program. Herein, those steps are described in detail.

\section{Step 1: Recruitment}

PERC used digital, audio, print, and in-person recruitment methods to disseminate the PA opportunity throughout the health system and in the surrounding community. For digital recruitment, a dedicated webpage was created solely for PAs (https://www.henryford.com/visitors/ perc/patient-advisor) that contained information about the program, informational videos, and a short online application. After monitoring site traffic and analytics, it became clear that additional communication methods were needed to drive interested parties to the website to apply. A recruitment ad was placed on the health system's main website as well as in a daily systemwide employee e-newsletter. In addition, an informational PERC message was placed on the health system's call waiting line as an audible recruitment method/tool. These efforts resulted in a total of 194 PAs by the end of 2015, surpassing the first recruitment goal of 150 advisors.

For print marketing, a quarterly newsletter was disseminated to current PAs and community groups. The newsletter served as a dissemination tool to share recent patient-centered outcomes research news, highlight a PA and a community group, and share the accomplishments of the various PA placements. The newsletter was disseminated at public events and made available online. A detachable insert was added to all newsletters advertising the PA opportunity, thus enabling recipients the ability to easily share the information. Additionally, recruitment brochures were created and placed in clinic waiting rooms.

Numerous PAs indicated that if their doctor recommended them to the PA program, they would be more likely to apply. In response, a nomination card process was created to leverage these physician-patient relationships. Providers were asked to give the cards to patients and caregivers who they felt would be a good fit for the program. The card directed interested participants to the PA website where they could learn more and apply.

In addition to the provider nominations, PERC encouraged PAs to nominate their family and friends. As a result, several married couples have been active in the program, which helped to increase the recruitment of men to $22 \%$ of participants. All recruitment methods directed interested parties to the PA website where they could apply online to become a PA. After submission of a short online application containing contact information, applicant interests, and schedule availability, the applicant moves to the next step in the process.

\section{Step 2: Informal Screening Interview}

An informal screening was added to the recruitment process to better ascertain potential advisors' suitability for the various PA roles and available projects. Once the online application was received by PERC staff, a followup call was scheduled, and the PERC recruiter would ask 8 questions (Table 1). These questions were adapted from Institute for Patient- and Family-Centered Care 


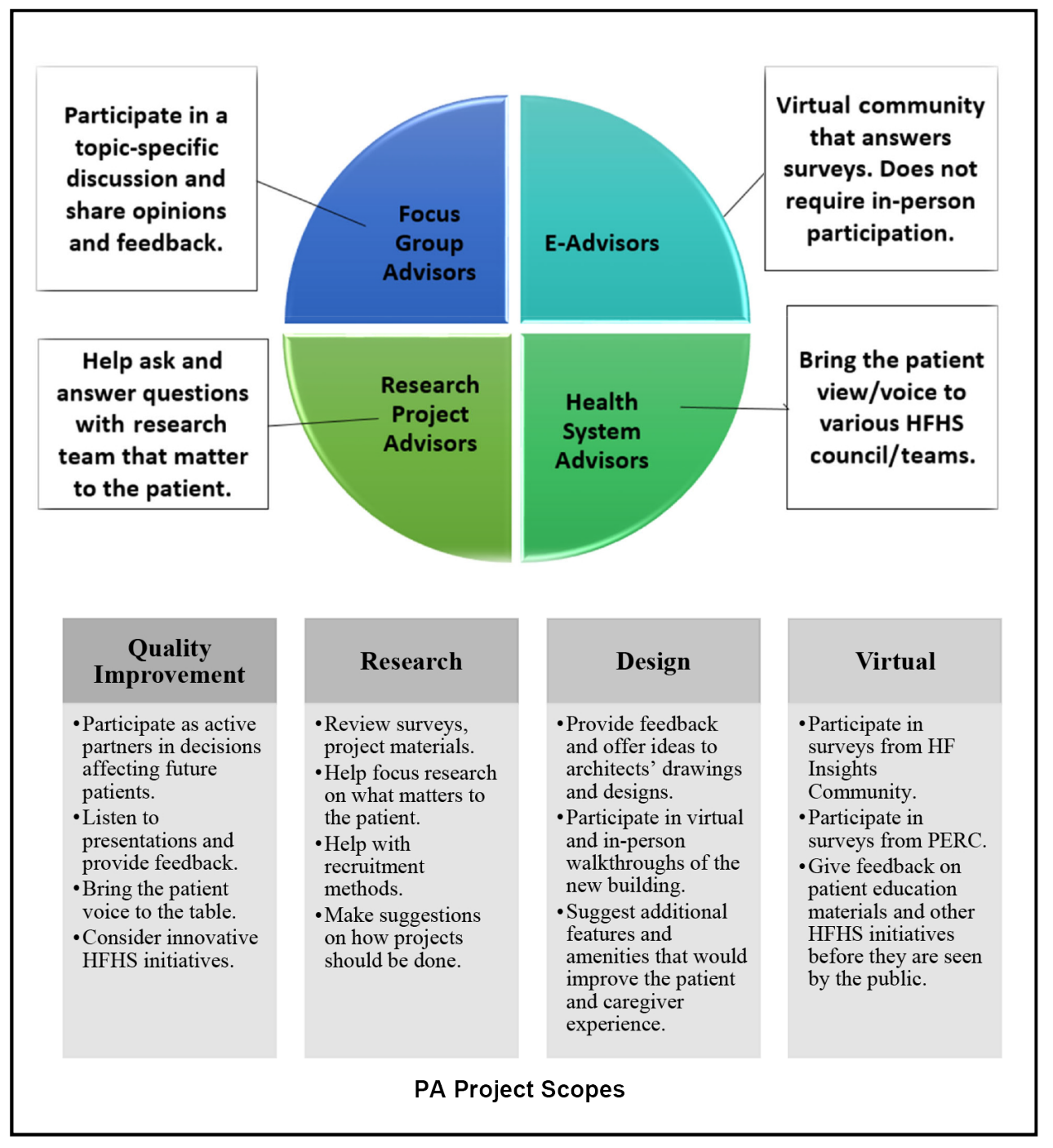

Figure 1. Patient advisor roles (top) and project scopes (bottom). HFHS, Henry Ford Health System; PERC, Patient-Engaged Research Center.
(IPFCC) resources ${ }^{16}$ and chosen to provide perspective on applicant experiences and insight into their problemsolving and group-work skills. Screening interview answers along with contact information were stored in customer relationship management (CRM) software (Insightly, Inc.).

\section{Step 3: Welcome Workshop}

Once an applicant completed the informal screening, they were invited to an orientation called the "Welcome Workshop," which provided more information about program infrastructure, the four PA roles, skill-based training, and a networking opportunity. The workshop accommodated 4-15 attendees, could be done in any meeting space that has audio/visual capacity, and was available as an ad hoc session if PAs needed a refresher. The PERC team utilized a core template for the Welcome Workshop that could be easily modified and customized for specific audiences. For example, for PAs advising on research studies, the Welcome Workshop includes research basics, jargon, and ethics. To accommodate accessibility needs during the COVID-19 pandemic, the workshop was adapted to be facilitated virtually.

The first component of the Welcome Workshop was devoted to institution-specific information such as emergency protocol, hospital policies, and HIPAA privacy regulations. Attendees sign a confidentiality agreement, and a code of conduct agreement was added as a workshop improvement to call attention to meeting attendance requirements and general conduct expectations. The second component of the workshop goes through the PA roles and project scopes and contains a skill-building element centered on the S.H.A.R.E acronym (solutionoriented, helpful, active listener, respectful, and effective communicator) created to highlight characteristics of successful PAs. 
Table 1. Informal Screening Questions

1. In what way have you interacted with the organization/ institution? As a patient or through a family member?

2. How has your experience been with your health care? Have your experiences been mostly good, mostly bad or mixture of both?

3. What interests you about being a patient advisor?

4. What do you hope to contribute as a patient advisor?

5. What do you hope to gain as a patient advisor?

6. Have you ever served on a committee, or worked with other group members? Do you find it easy to share your opinions with others?

7. What would you do if you felt very strongly about something and someone else in the group had a different opinion? How did you handle it?

8. If you had a magic wand, and could change/improve the health care experience for you, your family and others, what would you change?

Storytelling, another component of the Welcome Workshop, is a crucial PA skill. PAs are expected to use storytelling to introduce themselves in meetings and to share how their role as a PA was inspired by their past experiences. ${ }^{17}$ The objective of the storytelling activity was to provide a safe space for PAs to share their experiences, receive feedback, and refine their stories to be succinct and effective in their delivery. Recognizing its importance, a significant amount of time and facilitator feedback was devoted to perfecting this skill. This activity has evolved over time to be more in depth, as it was recognized that PAs need to feel comfortable with sharing their story in a public forum. What started as a 10-15-minute activity expanded into a 30-40-minute activity to allow more time to practice. PERC has observed PAs are more effective sharing their story having had extensive practice during the workshop training.

At the end of the Welcome Workshop, PAs completed a self-report demographic survey and evaluated meeting content, logistics, and facilitators, indicating their agreement with statements on a 5-point Likert-type response scale ranging from 1 (strongly negative) to 5 (strongly positive). Their next touchpoint with the PA program was receiving the monthly email with project opportunities (E-blast), described further in Step 6. A PA was considered "active" after completing the workshop and at least one of the following: 1) participation in at least one in-person event quarterly, 2) emailing PERC or responding to an email within the last month, or 3 ) opening of the most recent E-blast. If this criterion was not met, the PA was considered "inactive." Inactive PAs received a "wellness check" from PERC staff to assess interest in continuing participation.

\section{Step 4: PA Project Assignment}

PAs participated on projects in two ways, either as a member of a patient and family advisory council (PFAC) or as an individual placement. A PFAC was a group of 15-20 PAs who collectively drove meeting agendas by identifying priorities and topics they would like to focus on through a standardized strategic planning process. They created work plans and partnered with their PA buddy, who served as a liaison between the PFAC and the health system or research project (further described in Step 5). For individual placements, 1-2 PAs served as patient representatives on an existing health system council, committee, or research project. In contrast to PFACs, these agendas were driven by the health system employees, and PAs served as a voice for the patient/ study participant experience.

Participation and sustained engagement of PAs is fundamental to the FEM. One integral element was finding "a place for every voice." If a PA's interest did not align with currently available projects, PERC pursued opportunities to create new projects that would be more closely aligned. The flexible nature of the FEM lies in the ability for PAs to transition seamlessly between any of the four PA roles noted in Figure 1. For example, a head and neck cancer PFAC started by working on quality improvement projects within an otolaryngology clinic. After 1 year of working on QI projects and establishing a solid foundation of patient engagement and brainstorming patient-engaged research ideas, this PFAC was awarded PCORI funding through a Pipeline to Proposal award and transitioned to the topic of strengthening engagement and building capacity in preparation to apply for further PCORI research funding. ${ }^{18,19}$ Other research projects also have utilized the FEM model to successfully engage and retain stakeholders and have published on topics covering women's health, childhood asthma, and well-child visits..$^{20-28}$

One unique aspect of the PA program is its ability to match a PA to a project based on expertise, mutual interests, and project needs. To identify potential patient engagement projects, PERC marketed the PA program within the health system via the PA website, employee newsletter, and presentations at department meetings. Interested parties could then submit an intake form with their project scope and needs. PERC worked with these interested parties to design their project to be more patientcentered. Additionally, to spark interest, PERC identified physicians and senior leadership PFAC champions who would promote PERC's resources and the PA program around the health system.

To market available placements, the monthly E-blast sent to the PA pool included available placements and other 
program information (see Step 6). PAs could express interest in projects via email or phone call, and PERC staff followed up to ensure the PA and the project were a good match. To ensure a smooth transition from the PA pool to the assigned project, PERC facilitated an introduction and "warm handoff" meeting between PA(s) and the PA buddy. PERC researchers have observed an appreciation for the warm handoff approach and found it to be essential in ensuring smooth transitions.

\section{Step 5: PA Buddy}

The PA buddy is a health system staff member who is knowledgeable about the PA placement and serves as the liaison between the PA(s), the project/committee, and PERC. Every PA buddy completed a mandatory online training module and was responsible for preparing a PA before, supporting during, and checking in after meetings. PAs indicated that a PA buddy made them feel more informed and comfortable in their roles. PA buddies helped PAs adjust to individual project cultures and could advocate on their behalf. For quality improvement purposes, PA buddies submitted meeting attendance, agendas, and minutes and participated in bimonthly PA buddy calls to discuss successes, challenges, and learnings.

All placement documentation was stored and shared electronically in a central data warehouse, enabling best practice sharing across placements. A patient engagement playbook was created as a resource to standardize and simplify the engagement process for interested collaborators and to serve as a roadmap for the PA program onboarding process. ${ }^{29}$

\section{Step 6: Retention}

All PAs in the Insightly ${ }^{\circledR}$ CRM database were systematically engaged using retention activities in the FEM. To continuously engage and retain, PERC employed a monthly touchpoint policy, communicating with the PAs at least once a month either virtually or in person. Through trial and error and continuous PA feedback, this timing was determined to be the most effective in keeping the program at the front of advisors' minds.

Used for both recruitment and retention purposes, the monthly E-blast was disseminated to all PAs, both "active" and "inactive." Inactive PAs were included in the hope that some may reengage after receiving monthly program communication. The E-blast kept PAs abreast of program and health system news and provided a platform to highlight PA accomplishments. Utilizing the marketing automation platform and email marketing service Mailchimp ${ }^{\circledR}$ (The Rocket Science Group), these E-blasts became effective tools to gauge the reach of PERC's engagement and retention digital strategies. PERC staff closely monitored PA program email activity and used data analytics to regularly refine recruitment methods and evaluate their effectiveness.

In addition to monthly E-blasts, PAs received many opportunities to complete online surveys. SurveyMonkey ${ }^{\circledR}$ and REDCap ${ }^{\circledR 30}$ were used to disseminate the surveys to PAs and track responses. Results of the surveys were always shared with the PAs to "close the communication loop." Sharing results shows PAs that their feedback was heard, how the information was used to change or improve research or health care, and reinforces the value of participation.

Annually, since 2017, PERC has hosted PA retreats where PAs can network with health system leaders and community stakeholders, celebrate accomplishments, and participate in skill-building exercises. PA retreat evaluations have consistently indicated the importance of having senior leadership speak to validate the necessity of PAs. Past PA retreats have averaged 75-100 participants and featured nationally renowned leaders in patient engagement and advocacy, a poster session highlighting PA project accomplishments, and a skill-building session on basic data analysis in research.

\section{Step 7: Dissemination}

Encouraging PAs to attend and present at local and national symposiums/conferences was the most effective dissemination method employed by PERC. PAs used these platforms to share their experiences as well as their PA journey. Thus far, PAs have attended and presented at 3 of PERC's PA retreats and numerous topic-specific health system symposiums as well as local, regional, and national academic and patient-advocate conferences. In addition, PAs have participated in dissemination videos and co-authored published white papers; one group created T-shirts to share their patient-engaged work on cancer precision medicine. ${ }^{31-35}$

\section{Sustainability}

Often, research cores like PERC are created through infrastructure grants. At the end of the funding period, without a plan for additional revenue streams, these cores become financially unsustainable. The funds required annually to support PERC's centralized infrastructure (1 FTE PhD/MPH/epidemiologist, $1 \mathrm{FTE}$ administrative coordinator, 0.5 FTE executive director, plus budget for marketing, travel, staff education, publication development, and national presentations) are approximately $\$ 150,000$. By demonstrating the return of value of PERC's resources to its funders, PERC has strategically garnered a broad array of financial support from internal health system funding, external grant funding, and philanthropic support for special events. 
The health system has allocated dedicated internal funds to cover approximately $40 \%$ of PERC's annual budget, specifically to support work related to system PFACs and engagement core activities, a key part of the FEM. Another source of internal funds (10\% of PERC's budget) is an endowed chair awarded to the AHRQ R24 grant's principal investigator (C.C.J.). These relationships and funding enable PERC to identify and develop research opportunities across the health system, which leads to our second area of revenue, external grant funding. Besides PERC's foundational grant, Henry Ford-based researchers have been awarded more than $\$ 1$ million in external funding from PCORI and AHRQ. Additionally, Henry Ford is one of 10 health provider organizations that are part of the National Institutes of Health's All of Us Research Program, of which PERC has been a vital component. Thus, external funding contributes to approximately $50 \%$ of PERC's annual budget. Finally, as opportunities arise for philanthropic support, PERC has secured PCORI and IPFCC funds to cover special events (eg, PA retreat), travel and education for staff, and for PAs to attend annual meetings.

Although measuring success and return on investment related to patient-centered work is difficult from a health system or research perspective, ${ }^{36-38}$ these diverse revenue streams and PERC's documented results and value to funders continue to sustain its research core 2 years after the end of the foundational AHRQ grant.

\section{RESULTS}

Table 2 outlines the success of various recruitment methods and demonstrates poster, mail, and email marketing was the most successful, recruiting 506 $(85.2 \%)$ PAs. Provider nominations were most effective for projects in the clinical environment or those with very specific eligibility requirements for participation. The rapid PA program participant growth between Q4 2015 and Q3 2016 (Figure 2) was attributed to the systemwide hold call message implemented at the end of 2015 .

At the time of this writing, there were 419 PAs in the program, $406(86.8 \%)$ of whom are active PAs (Table 3$)$. The PA can opt out of the program at any time, which $51(10.6 \%)$ did. Unfortunately, PERC had to terminate 9 (1.9\%) PAs for unprofessional, noncompliant behavior defined by the code of conduct discussed at orientation. Table 4 shows the demographics of the 406 active PAs. By self-report, the PA population consisted of 50\% Caucasians and 31\% African Americans; $73 \%$ of participants were women and the majority $(64 \%)$ of the PAs were between 45 and 74 years old. Compared to Henry Ford's overall 2019 patient population (Table 4),
Table 2. Patient Advisor Recruitment Methods

\begin{tabular}{lc}
\hline $\begin{array}{l}\text { "How did you hear about the } \\
\text { Patient Advisor opportunity?" }\end{array}$ & $\begin{array}{c}\text { n (\%) of } 594 \\
\text { total leads* }\end{array}$ \\
\hline $\begin{array}{l}\text { Posters, mail, email (including internal and } \\
\text { external newsletters, brochures, etc) }\end{array}$ & $506(85.2 \%)$ \\
Henry Ford hold call message & $36(6.1 \%)$ \\
Doctor, nurse, provider & $18(3.0 \%)$ \\
Found while browsing the internet & $15(2.5 \%)$ \\
Word of mouth & $10(1.7 \%)$ \\
Nomination card & $9(1.5 \%)$ \\
\hline
\end{tabular}

*Leads are defined by anyone who submits an application to be a patient advisor.

the PA program was representative in age and race, but disproportionately higher in female sex, than the larger patient population.

Figure 3 shows overall Welcome Workshop satisfaction categories, including for content, facilitators, and logistics. Overall, the PAs were very satisfied with the quality of the content and facilitators, ranking each question within those groups, on average, between 4.5 and 5 on a 5 -point scale. At times, PAs indicated slight dissatisfaction with meeting logistics, such as room temperature or food options.

The PA program has grown steadily since its inception in December 2014. Figure 2 reports both the number of PAs and projects, combining the number of PFACs and individual projects, by quarter, from 2015 to the end of 2019. As part of an annual strategic planning process, PERC set two recruitment goals, designated by horizontal dashed lines in Figure 2, and surpassed both goals ahead of schedule by using a pragmatic trial and error approach to recruitment strategies. PERC's robust administrative capacity, paired with constant review of recruitment strategy efficiency, resulted in continued steady growth through 2019. In 2020, PERC adapted to the COVID-19 pandemic by supporting virtual PA project meetings and facilitating virtual orientations and networking opportunities.

\section{DISCUSSION}

The FEM has proved to be an effective model that, when customized to meet specific organizational needs, can establish a sustainable patient engagement resource. PERC's most valuable resource is its PA pool. A variety of recruitment methods were used, with the most successful 


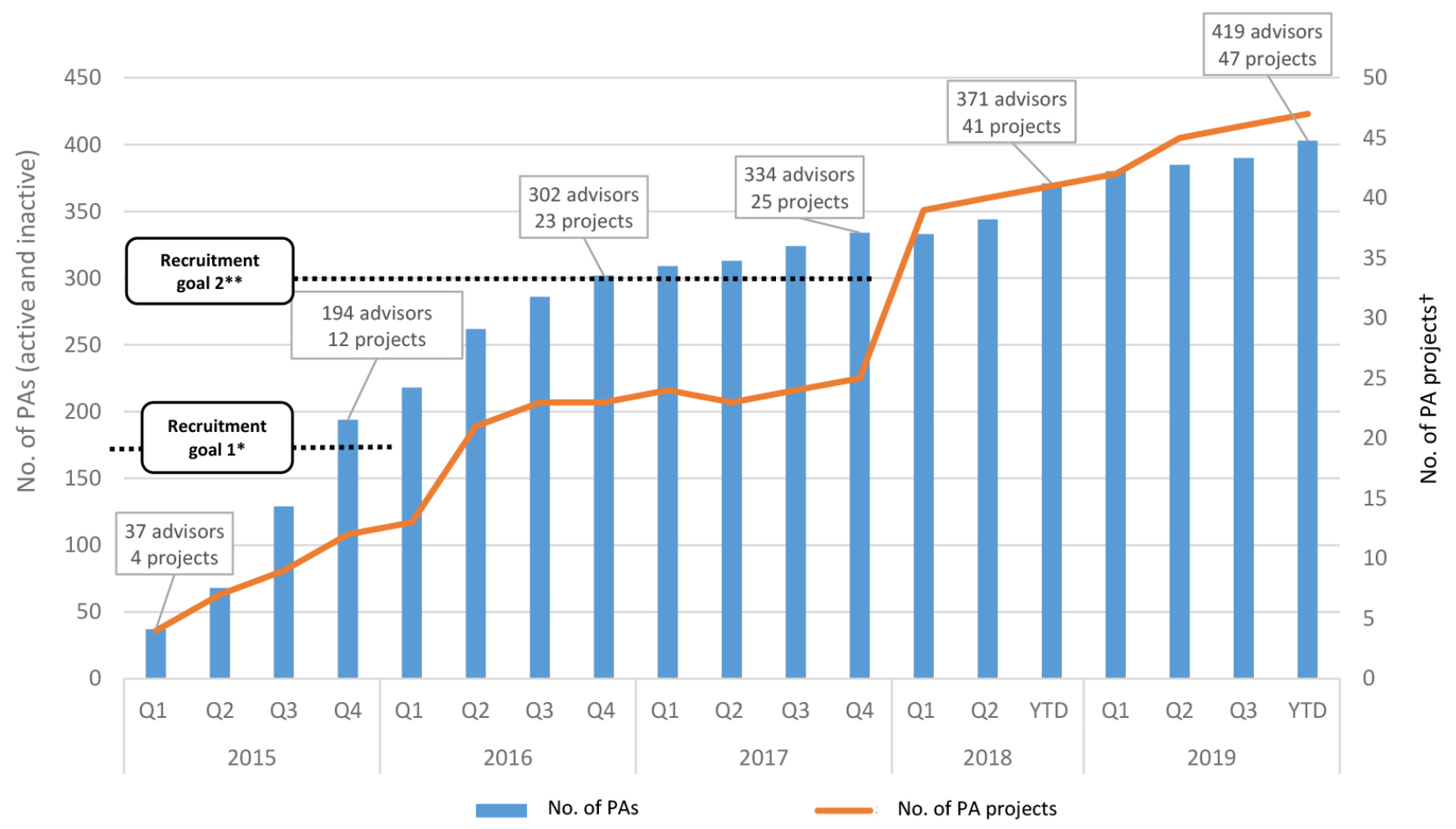

Figure 2. Patient advisor (PA) program growth, 2015-2019. *Recruitment goal 1: To recruit 150 PAs by the end of Q4 2015. **Recruitment goal 2: To recruit 300 PAs by the end of Q4 2017. 'Includes both patient and family advisory councils and individual placements.

being posters, mail, and email. Moreover, it appears PAs are satisfied with program onboarding, and growth and sustainability are both evident.

Future enhancements to the recruitment may be to tailor message content, mode, or messenger (ie, physician, nurse, family member) to continue developing a diverse PA pool. Specifically, the current PA program experiences higher dropout rates and low recruitment of certain demographic groups; however, PERC consistently refines recruitment strategies to better target underrepresented demographic groups such as males and younger patients. For example, literature suggests that online platforms act as a tool for inclusivity for improving participation in diverse sociodemographic groups ${ }^{39}$ Thus, to recruit a younger demographic, a digital PFAC was established with direct recruitment through email to male patients who are $<45$ years old and had a primary care appointment within the last 6 months. Meetings were scheduled in the evening after work.

PERC learned that ensuring PA voices are heard and valued is essential to program engagement and retention. Through verbal and written feedback, PAs have shared they appreciated frequent updates acknowledging the value of their contributions. Creating a safe environment through meeting planning and facilitation is essential to the PAs authentically and freely sharing their feedback and experiences. PERC emphasizes there are no right or wrong answers, always thanks PAs for their contributions, determines feasibility of implementation offline, and communicates final outcomes or continues discussions.

Similar to the Henry Ford FEM, there are other patient engagement models that aim to recruit, train, and assign advisors to placements around a health system or organization, but most of those models focus solely on quality and safety projects to leverage the patient voice. This FEM distinguishes itself from other engagement models by seamlessly and simultaneously integrating patient engagement projects that go beyond quality and safety and encompass opportunities like building design and patientcentered research. ${ }^{40-43}$ Keeping up with supply and demand of available PA projects has been a challenge, therefore ensuring programming was created to keep nonassigned PAs engaged during slow periods was essential to program retention. At times there were not enough available placements for unassigned PAs or the available placements did not appeal to the interest of the PAs. 
Table 3. Patient Advisor Program Involvement ${ }^{a}\left(\mathrm{~N}=479^{\mathrm{b}}\right)$

\begin{tabular}{|c|c|c|}
\hline Status & Status definition & n (\%) \\
\hline Active & $\begin{array}{l}\text { Participant receives all correspondence, attends meetings } \\
\text { and events, and has NOT opted out of the program. }\end{array}$ & $406(84.8 \%)^{c}$ \\
\hline Declined to participate & $\begin{array}{c}\text { Participant has opted out of receiving all program } \\
\text { communications. }\end{array}$ & $51(10.6 \%)$ \\
\hline Inactive/Lost to follow-up & $\begin{array}{l}\text { Exceeded attempts to contact and staff can't get in touch } \\
\text { with advisor. Advisor does not open email correspondence } \\
\text { or participate in events. }\end{array}$ & $13(2.7 \%)^{c}$ \\
\hline Terminated & $\begin{array}{c}\text { Advisor has opted out of receiving all correspondence from } \\
\text { the patient advisor program. }\end{array}$ & $9(1.9 \%)$ \\
\hline
\end{tabular}

${ }^{a}$ As of December 31, 2019.

${ }^{b}$ Total number of people who were screened to become patient advisors. This number includes active, declined to participate, inactive, and terminated patient advisors.

${ }^{\circ}$ Only participants of active or inactive status comprised the patient advisor program population analysis $(n=419)$.

Table 4. Demographics of the Patient Advisor Program and the Henry Ford Health System (HFHS) at Large

\begin{tabular}{|c|c|c|}
\hline Demographic & $\begin{array}{l}\text { Active/inactive patient advisors, } \\
2015-\text { present }^{\mathrm{a}}(\mathrm{n}=419)\end{array}$ & $\begin{array}{l}\text { HFHS patient population, } \\
2019^{\mathrm{b}}(\mathrm{N}=1,044,001)\end{array}$ \\
\hline \multicolumn{3}{|l|}{ Age, n (\%) } \\
\hline $13-18$ years & $5(1.19 \%)$ & $61,724(5.91 \%)$ \\
\hline 19-24 years & $5(1.19 \%)$ & $74,845(7.17 \%)$ \\
\hline 25-34 years & $16(3.82 \%)$ & $134,548(12.89 \%)$ \\
\hline $35-44$ years & $39(9.31 \%)$ & $119,250(11.42 \%)$ \\
\hline $45-54$ years & $67(15.99 \%)$ & $145,246(13.91 \%)$ \\
\hline $55-64$ years & $114(27.21 \%)$ & $164,939(15.80 \%)$ \\
\hline $65-74$ years & $89(21.24 \%)$ & $127,875(12.25 \%)$ \\
\hline $75-84$ years & $16(3.82 \%)$ & $67,094(6.43 \%)$ \\
\hline Declined to answer/Unknown & $68(16.23 \%)$ & - \\
\hline \multicolumn{3}{|l|}{ Sex, n (\%) } \\
\hline Female & $303(72.32 \%)$ & $589,847(56.50 \%)$ \\
\hline Male & $92(21.96 \%)$ & $453,839(43.47 \%)$ \\
\hline Declined to answer/Unknown & $24(5.73 \%)$ & $315(0.03 \%)$ \\
\hline \multicolumn{3}{|l|}{ Race, n (\%) } \\
\hline Caucasian/White & $207(49.40 \%)$ & $638,685(61.18 \%)$ \\
\hline African American/Black & $130(31.02 \%)$ & $242,336(23.21 \%)$ \\
\hline Asian & $8(1.91 \%)$ & $26,579(2.55 \%)$ \\
\hline American Indian/Alaskan Native & $1(0.24 \%)$ & $4355(0.42 \%)$ \\
\hline Other & $6(1.43 \%)$ & $43,133(4.13 \%)$ \\
\hline Declined to answer & $67(15.99 \%)$ & $88,913(8.52 \%)$ \\
\hline \multicolumn{3}{|l|}{ Ethnicity, n (\%) } \\
\hline Hispanic/Latino & $3(0.72 \%)$ & $36,311(3.48 \%)$ \\
\hline Arab/Chaldeanc & $7(1.67 \%)$ & - \\
\hline
\end{tabular}

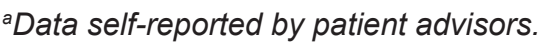

${ }^{b}$ Data sources: HFHS population database laboratory; HFHS Epic electronic health records.

'Data on Arab/Chaldean descent is not currently collected by HFHS metrics. 


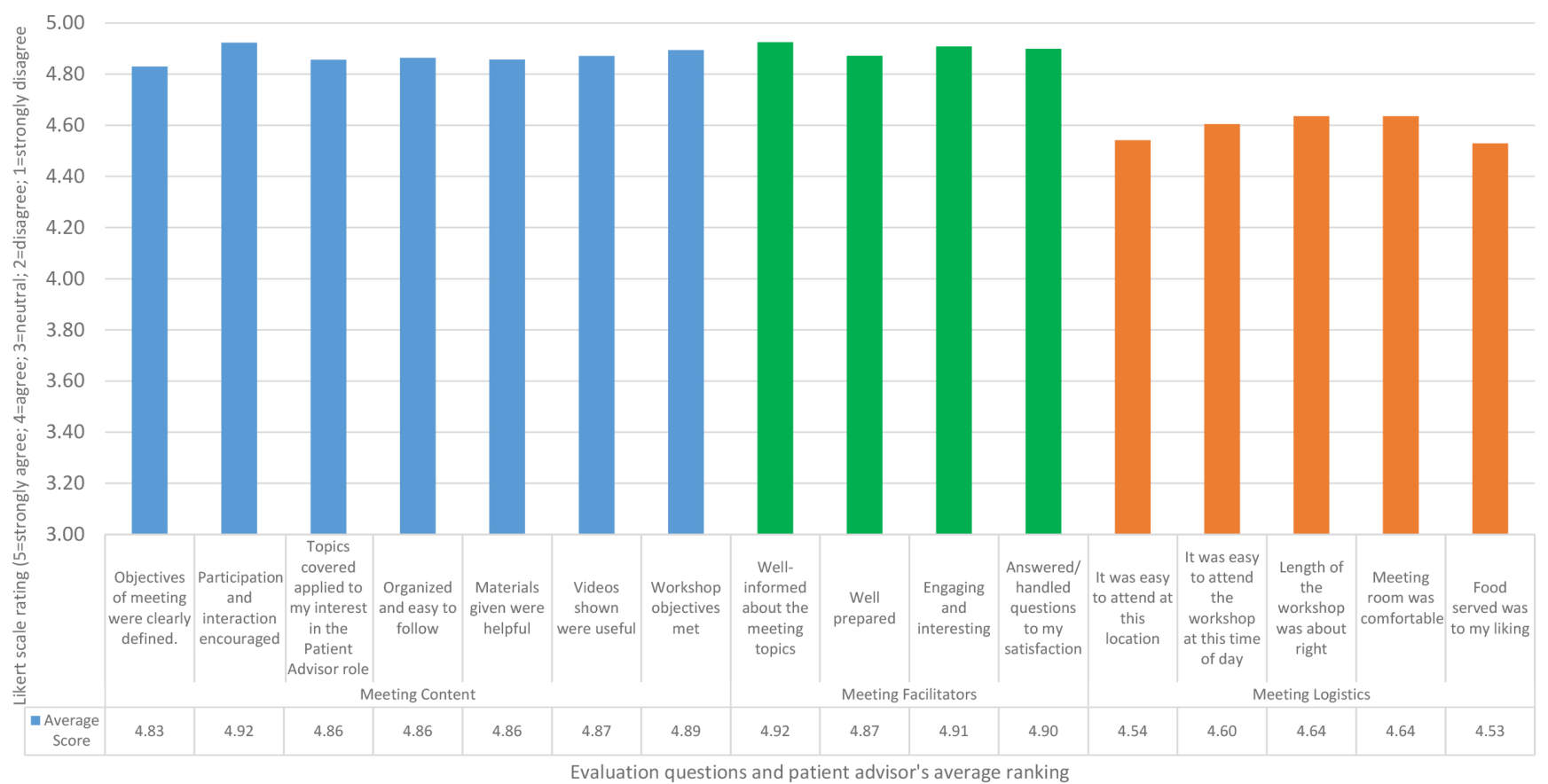

Figure 3. Welcome Workshop satisfaction scores (2015-2019).

Given the nature of patient-centered research and its similarities to community based participatory research (CBPR), ${ }^{44-46}$ the FEM could be further modified by incorporating the CBPR framework and principles to make the model more applicable outside of health system environments. Furthermore, the FEM could explore the impact of incentives for providers and administration, both formal and informal, to pursue patient-centered projects and grant funding. Finally, further research could focus on the model's return on investment and how to embed its methodology institutionally so that patient engagement becomes an integral part of culture and decision-making.

\section{CONCLUSIONS}

Henry Ford's flexible engagement model offers a mechanism for approaching patient engagement that provides patient advisors the opportunity to flex between placements of varying topics, including quality improvement, patient-centered research, and design. Its flexible nature also allows for virtual participation at the patient's convenience, which demonstrated FEM's sustainability and capability to adapt during the COVID-19 pandemic. While the FEM is meant to be adapted to the institution where it is being utilized, operationalizing those adaptations and testing the model in other health systems of varying sizes could further validate the model's generalizability.

\section{Patient-Friendly Recap}

- Health care and research organizations can benefit by listening to and learning from patient input on nonclinical aspects of care and research processes. An effective patient advisor program engages a diverse group willing to contribute their experiences and feedback to improve research projects and care outcomes.

- In the flexible engagement model presented, applicants were guided through an orientation workshop and communication training to prepare them for advisory roles. This approach helped researchers match each advisor's skills and passions to suitable projects.

- Maintaining a consistent feedback loop that confirms patient voices are being heard is important to keeping patient advisors engaged.

\section{Acknowledgments}

The Patient-Engaged Research Center would like to acknowledge the patient advisors for their continuous participation and support. 


\section{Author Contributions}

Study design: Olden, Murphy, Johnson, Kippen. Data acquisition or analysis: Olden, Murphy, Johnson, Kippen. Manuscript drafting: all authors. Critical revision: all authors.

\section{Conflicts of Interest}

None.

\section{Funding Sources}

This work was funded by the Agency for Healthcare Research and Quality (award no. R24 HS022417), a National Institutes of Health All of Us Research Program OT-2 Award (\#OT2OD026550), and Patient-Centered Outcomes Research Institute grants \#60815, $\# 3411283$, and \#5136893 and contracts \#C827, \#7159, \#3865, and \#3867.

\section{References}

1. Patient-Centered Outcomes Research Institute. Glossary. Accessed Jan 5, 2019. https://www.pcori.org/glossary

2. Keddem S, Agha AZ, Long JA, Werner RM, Shea JA. Creating a toolkit to reduce disparities in patient engagement. Med Care. 2017;55 Suppl 9 Suppl 2:S59-69. CrossRef

3. Agha AZ, Werner RM, Keddem S, Huseman, TL, Long JA, Shea JA. Improving patient-centered care: how clinical staff overcome barriers to patient engagement at the VHA. Med Care. 2018;56:1009-17. CrossRef

4. Evon DM, Golin CE, Stewart P, et al. Patient engagement and study design of PROP UP: a multi-site patient-centered prospective observational study of patients undergoing hepatitis C treatment. Contemp Clin Trials. 2017;57:58-68. CrossRef

5. LaNoue M, Mills G, Cunningham A, Sharbaugh A. Concept mapping as a method to engage patients in clinical quality improvement. Ann Fam Med. 2016;14:370-6. CrossRef

6. Sharma AE, Grumbach K. Engaging patients in primary care practice transformation: theory, evidence and practice. Fam Pract. 2017;34:262-7. CrossRef

7. Vandigo J, Oloyede E, Aly A, Laird AL, Cooke CE, Mullins CD. Continuous patient engagement in cardiovascular disease clinical comparative effectiveness research. Expert Rev Pharmacoecon Outcomes Res. 2016;16:193-8. CrossRef

8. Laurance J, Henderson S, Howitt PJ, et al. Patient engagement: four case studies that highlight the potential for improved health outcomes and reduced costs. Health Aff (Millwood). 2014;33:1627-34. CrossRef

9. Carman KL, Dardess P, Maurer M, et al. Patient and family engagement: a framework for understanding the elements and developing interventions and policies: Health Aff (Millwood). 2013;32:223-31. CrossRef

10. Lamberti MJ, Awatin J. Mapping the landscape of patientcentric activities within clinical research. Clin Ther. 2017;39:2196-202. CrossRef

11. Lee DJ, Avulova S, Conwill R, Barocas DA. Patient engagement in the design and execution of urologic oncology research. Urol Oncol. 2017;35:552-8. CrossRef

12. Perestelo-Pérez L, Rivero-Santana A, Abt-Sacks A, et al. Patient empowerment and involvement in research. Adv Exp Med Biol. 2017;1031:249-64. CrossRef

13. Esmail L, Moore E, Rein A. Evaluating patient and stakeholder engagement in research: moving from theory to practice. J Comp Eff Res. 2015;4:133-45. CrossRef
14. Concannon TW, Fuster M, Saunders T, et al. A systematic review of stakeholder engagement in comparative effectiveness and patient-centered outcomes research. J Gen Intern Med. 2014;29:1692-701. CrossRef

15. Schmittdiel JA, Desai J, Schroeder EB, et al. Methods for engaging stakeholders in comparative effectiveness research: a patient-centered approach to improving diabetes care. Healthc (Amst). 2015;3:80-8. CrossRef

16. Institute for Patient- and Family-Centered Care. Free downloads: reports/roadmaps. Accessed January 15, 2019. http://www.ipfcc.org/resources/downloads-tools.html

17. Morrise L, Stevens KJ. Training patient and family storytellers and patient and family faculty. Perm J. 2013;17:e142-5. CrossRef

18. Iwata AJ, Olden HA, Kippen, KE, Swegal WC, Johnson CC, Chang SS. Flexible model for patient engagement: achieving quality outcomes and building a research agenda for head and neck cancer. Head Neck. 2019;41:1087-93. CrossRef

19. Iwata AJ, Olden HA, Kippen KE, Swegal WC, Chang S. Patient driven efforts for quality outcomes and research in head and neck cancer. (abstr.) J Clin Oncol. 2018;36(15_suppl):e22065. CrossRef

20. Bossick AS, Roopina S, Olden HA, Alexander GL, Wegienka G. Identifying what matters to hysterectomy patients: postsurgery perceptions, beliefs, and experiences. J Patient Cent Res Rev. 2018;5:167-75. CrossRef

21. Bossick AS, Barone C, Alexander GL, Olden H, Troy T, Cassidy-Bushrow AE. Teen, parent, and clinician expectations about obesity and related conditions during the annual well-child visit. J Patient Cent Res Rev. 2017;4:114-24. CrossRef

22. Alexander GL, Olden HA, Troy T, Miree CA, Joseph CLM. Overweight adolescents and asthma: revealing motivations and challenges with adolescent-provider communication. J Asthma. 2017;55:266-74. CrossRef

23. Bossick AS, Alexander G, Troy T, Olden H, Barone C, Cassidy-Bushrow AE. Weight-related messages in well-child visits: What do teens desire? (abstr.) J Patient Cent Res Rev. 2016;3:219-20. CrossRef

24. Patient-Centered Outcomes Research Institute. Engaging patients and other stakeholders to develop a patient-centered research agenda for cancer precision medicine. Last updated December 26, 2019; accessed December 26, 2019. https:// www.pcori.org/research-results/2016/engaging-patients-andother-stakeholders-develop-patient-centered-research

25. Patient-Centered Outcomes Research Institute. Transforming the gift of life into a Transplant Living Community - tier II. Last updated November 23, 2021; accessed May 30, 2018. https://www.pcori.org/research-results/2017/transforminggift-life-transplant-living-community-tlc-tier-ii

26. Patient-Centered Outcomes Research Institute. Focus on the rainbow. Last updated November 23, 2021; accessed December 26, 2019. https://www.pcori.org/research-results/2016/focusrainbow

27. Patient-Centered Outcomes Research Institute. Motor City School Health Collaborative. Last updated November 23, 2021; accessed March 27, 2020. https://www.pcori.org/ research-results/2017/motor-city-school-health-collaborative

28. National Institutes of Health. Welcome to the All of Us Research Hub. Accessed October 30, 2020. https://www. researchallofus.org 
29. Henry Ford Health System. Patient engagement playbook. Accessed February 15, 2021. https://www.henryford.com/ visitors/perc/patient-engagement-process-henry-fordemployees

30. Cassidy-Bushrow AE, Baseer M, Kippen K, et al. Social distancing during the COVID-19 pandemic: quantifying the practice in Michigan - a "hotspot state" early in the pandemic - using a volunteer-based online survey. BMC Public Health. 2021;21(1):245. CrossRef

31. HenryFordTV on YouTube. Patient-Engaged Research Center (PERC). Posted December 10, 2014; accessed December 7, 2021. https://www.youtube.com/watch?v=iQ-M7wW8hqs

32. HenryFordTV on YouTube. The role of a patient advisor. Posted March 23, 2016; accessed December 7, 2021. https://www.

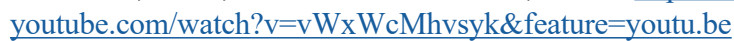

33. HenryFordTV on YouTube. Cancer precision medicine symposium. Posted July 18, 2017; accessed December 7, 2021. https://www.youtube.com/watch? v=w2 8r24SwWI

34. HenryFordTV on YouTube. What is precision medicine? Posted March 28, 2019; accessed December 7, 2021. https://www. youtube.com/watch? $\mathrm{v}=\mathrm{X} 3 \mathrm{SLs} 0--8 \mathrm{Vw} \&$ feature=youtu.be

35. Patient-Centered Outcomes Research Institute; Patient-Engaged Research Center Patient Advisors. Engaging patients and other stakeholders to develop a patient-centered research agenda for cancer precision medicine. (white paper.) Published December 19, 2018; accessed December 26, 2019. https://www.pcori.org/ sites/default/files/CaPM-White-Paper 121918.pdf

36. Domecq Garces JP, Prutsky Lopez GJ, Wang Z, et al. Eliciting patient perspective in patient-centered outcomes research: a meta narrative systematic review. Published in 2012; accessed December 7, 2021. https://www.pcori.org/assets/ElicitingPatient-Perspective-in-Patient-Centered-Outcomes-ResearchA-Meta-Narrative-Systematic-Review.pdf

37. Tritter JQ. Revolution or evolution: the challenges of conceptualizing patient and public involvement in a consumerist world. Health Expect. 2009;12:275-87. CrossRef

38. Mitton C, Smith N, Peacock S, Evoy B, Abelson J. Public participation in health care priority setting: a scoping review. Health Policy. 2009;91:219-28. CrossRef
39. van den Berg AC, Giest SN, Groeneveld SM, Kraaij, W. Inclusivity in online platforms: recruitment strategies for improving participation of diverse sociodemographic groups. Public Adm Rev. 2020;80:989-1000. CrossRef

40. Agency for Healthcare Research and Quality. Working with patients and families as advisors (implementation handbook). Accessed February 1, 2021. https://www.ahrq. gov/sites/default/files/wysiwyg/professionals/systems/ hospital/engagingfamilies/strategy $1 /$ Strat 1_Implement Hndbook 508 v2.pdf

41. Sharma AE, Knox M, Mleczko VL, Olayiwola JN. The impact of patient advisors on healthcare outcomes: a systematic review. BMC Health Serv Res. 2017;17:693. CrossRef

42. Colorado Hospital Association. Patient family advisory councils: 2019 toolkit. Accessed February 2, 2021. https://cha.com/wpcontent/uploads/2019/04/CHA.158-PFAC-Toolkit 2019 final.pdf

43. Schlaudecker J, Goodnow K, Goroncy A, et al. Meaningful partnerships: stages of development of a patient and family advisory council at a family medicine residency clinic. J Particip Med. 2019;11(1):e12105. CrossRef

44. Kwon SC, Tandon SD, Islam N, Riley L, Trinh-Shevrin C. Applying a community-based participatory research framework to patient and family engagement in the development of patient-centered outcomes research and practice. Transl Behav Med. 2018;8:683-91. CrossRef

45. Detroit Community-Academic Urban Research Center. What is CBPR? Accessed February 7, 2021. https://detroiturc.org/ about-cbpr/what-is-cbpr

46. Byers C. Community-based participatory research (CBPR): a framework for community engagement. Published December 9, 2020; accessed February 11, 2021. https://www.advarra. com/blog/community-based-participatory-research-cbpr-aframework-for-community-engagement/

(C) 2022 Advocate Aurora Health, Inc. 